\title{
Г.Г. Супрыгина
}

\section{ДЕТИ ГЕРМАНИИ В ПЕРВУЮ МИРОВУЮ ВОЙНУ}

\begin{abstract}
Статья посвящена почти неисследованной в отечественной литературе теме - детям Германии в годы Первой мировой войны. В ней выявлены глубокие изменения в положении детей в семье, школе, обществе. В работе показаны влияние голода на подрастающее поколение Германской империи в 1914-1918 гг., участие детей в решении семейных проблем. В статье анализируется политика вовлечения учащихся в кампании по укрепления тылового общества ради победы рейха; указываются основные направления пропаганды среди детей.

Ключевые слова: «фронт родины» Германии в Первой мировой войне; дети.
\end{abstract}

Первая мировая война, начало которой большинство немцев встретило с воодушевлением, вскоре принесла им тяжелые утраты и потери, которые в той или иной мере затронули каждую семью. На протяжении всей войны социально-экономическое положение тылового общества Германской империи ухудшалось. По данным немецкого исследователя Г.-У. Велера, за годы Первой мировой войны производство общественной продукции в рейхе сократилось на $60 \%$, реальная зарплата трудящихся упала на 30-40\%. Уже в первые месяцы войны рядовые немцы столкнулась с лишениями, голодом, болезнями, резким падением жизненного уровня. В январе 1915 г. были введены карточки на хлеб, затем рационирование было распространено почти на все продукты питания. В 1916 г. обеспеченность немцев мясом по сравнению с 1913 г. составила 31\%, в 1918 г. - 12\%, рыбой - 51 и 5\%, растительным маслом - 39 и 17\% соответственно. Потребление картофеля за годы войны сократилось на $71 \%$ [1. S. 70].

Дефицитом стали и товары повседневного спроса, поскольку первостепенной задачей правительства было снабжение армии, тыловому населению были предложены многочисленные эрзац-продукты и товары, которые изготавливались из некачественного сырья. Большинство родителей не могли обеспечить подрастающих детей качественной одеждой. Неспособность правительства снабжать население вскоре привела к возникновению черного рынка с непомерными ценами. Постоянным явлением военного времени стала инфляция, принявшая летом 1917 г. галопирующий характер. Всю войну острой проблемой населения тыла была нехватка топлива. Одной из причин бедственного положения немцев стала морская блокада Великобритании, которая отрезала Германию, почти не имеющую колоний, от региональных и мировых рынков, в том числе финансовых.

Уже в первые месяцы этой невиданной ранее по масштабам войны в положении детей ГИ произошли разительные перемены, они стали ее первыми жертвами. Большинство детей, прежде всего городских, вместе со взрослыми голодали и жили в неотапливаемых домах и квартирах. Миллионы семей остались без кор- мильца, так как за военные годы на фронт было призвано более 13,25 млн мужчин (что составило 85\% мужского населения в возрасте 17-50 лет) [2. S. 4]. Военные потери немцев составили 2 млн, в итоге 513 тыс. женщин остались вдовами, сиротами - 1,2 млн детей [1. S. 101]. Многие из них остались круглыми сиротами, поскольку из-за голода и болезней возросла и женская смертность: в 1916 г. она была на 11,5\% выше довоенной, в 1917 г. - даже на 30,4\% [3].

Катастрофическое положение с продовольствием в рейхе в первую очередь пагубно сказалось на детях. Все воюющие державы ощущали его нехватку, но нигде она не была столь острой, как в Германии, в которой за годы войны от голода погибло 763 тыс. человек, большинство из них были дети и пожилые люди. Особую уязвимость детей подтверждает статистика: к 1917 г. по сравнению с 1913 г. смертность их увеличилась на 50\% [4. S. 83].

Хроническое недоедание и переохлаждение ослабляли иммунитет детей, что привело к росту числа заболеваний среди них. Наиболее часто они страдали от анемии, туберкулеза, пневмонии, испанского гриппа и др. Медицинские обследования военного времени выявили большие отклонения в росте от сложившейся ранее нормы. Так, осмотры 1916/17 учебного года показали, что вес 14-летних подростков в среднем был меньше обычного на 2 кг. Рост учащихся народных и средних школ оказался ниже нормы на 2 см, в 1917/18 году - даже на 3 см. Среди первоклассников, пришедших в школу в сентябре 1917 г., малорослых было в три раза больше, чем в довоенный период [5].

Из-за неурожая картофеля и пшеницы, а также организационного хаоса самым тяжелым временем Первой мировой войны оказалась зима 1916-1917 г. Немцы назвали ее «брюквенной», поскольку в лавках предлагали только брюкву, которая для многих немцев была единственным пищей. «Брюквенная зима» стала символом «голода» в Первую мировую войну, от него в первую очередь страдали дети. На городских улицах нередко можно было встретить детей, которые просили у прохожих хлеб [6. S. 169].

Вальтер Кох, глава саксонского продовольственного ведомства в Дрездене (и редкий образец кристально 
честного чиновника), который не испытывал финансовых затруднений, но по моральным мотивам отказывался покупать дополнительное продовольствие на черном рынке, считая это вкладом семьи в победу рейха, оставил воспоминания об этом времени. В них Кох пишет, что сам он из-за недоедания потерял 15 кг своего веса, но самым тяжелым для него было видеть страдания детей: «У меня болезненно сжималось сердце, когда я смотрел на 15-летнего Манфреда и 11-летнюю Веру, которые приходили из школы и безмолвно бросались в кладовую или в буфет в поисках чего-нибудь съестного, чтобы утолить свой голод». Не менее печальной была его борьба с женой, которая свою и так скудную порцию подсовывала детям, подрывая свое здоровье [4. S. 85].

Чтобы хоть частично улучшить продовольственное снабжение особо бедствующих групп населения, органы местного самоуправления стали организовывать у школ, спортзалов и в других общественных местах «народные кухни». В определенное время нуждающиеся, в первую очередь дети, могли получить у полевых кухонь теплую пищу и хлеб. В годы войны такие «народные кухни» действовали в 2400 городах рейха, и они спасли многих детей от голодной смерти [6. S. 170].

Ощутимой поддержкой для малоимущих семей была и отправка детей для оздоровления из особо бедствующих городов в Голландию, Данию, Швецию. Наибольшее количество детей - 307,4 тыс. - за границу было отправлено в 1917 г. Но с конца 1917 г. число таких поездок резко сократилось в связи с подготовкой решающих наступлений на фронте. Военные власти крайне нуждались в транспортных средствах для перевозки войск, орудий, боеприпасов, раненых и перестали выделять поезда для эвакуации ослабленных детей [7].

Хотя на территории Германии военные действия почти не велись, но тяжелым испытанием для ее малолетних жителей стали сотни воздушных бомбардировок англо-французских авиаторов. Они начались в октябре 1914 г. с целью устрашения населения и уничтожения немецкой военной индустрии и продолжались всю войну. Их целью являлись военные заводы РурскоРейнской, Майнской, Саарской областей и Лотарингии, но жертвами бомбежек, особенно ночных, часто становились жители этих районов, в том числе дети, которые гибли или получали тяжелые увечья и стрессы [8. S. 34].

Радикально изменилась школьная жизнь учащихся. Уже в первые месяцы войны заметно снизилось качество обучения. Одной из причин этого явилась острая нехватка учителей, так как преобладающая их часть были мужчины, подлежащие призыву. Многие учителя, особенно городские, охваченные ура-патриотическими настроениями, не дожидаясь мобилизации, ушли на фронт добровольцами. Из-за отсутствия педагогов некоторые школы были даже вынуждены прекратить занятия. Но большинство из них все же продолжали обучение детей, поскольку их руководство привлекало к дополнительной (и часто неоплачиваемой) работе оставшихся коллег, учителей пенсионного возраста, студентов. Однако обучение проводилось по сокращенной программе, часто в одном помещении собиралось до 65 школьников из разных классов, с которыми занимался один учитель. В годы войны из учебных программ были исключены предметы, «не важные в условиях военного времени».

«Индустриальная война» 1914-1918 гг. сопровождалась применением новейшего оружия большой поражающей способности, что обусловило с первых дней невиданный ранее поток раненых. По распоряжению военного командования во многих школах размещались лазареты, а также командование, военные части, резервисты и ополчение. Для их переподготовки отводилась классы, спортзалы, школьные дворы, превращенные в плац, и все они стали недоступными для учащихся.

Число учебных занятий сокращалось и в связи с их отменой в дни празднований побед немецких вооруженных сил, в которых ученики должны были обязательно участвовать. Начало этой традиции заложили проведенные с большим размахом торжества по поводу победы немецких войск над русской армией в сражении под Танненбергом в Восточной Пруссии в августе 1914 г. За ними последовали празднества в честь победы Пруссии над Францией под Седаном 3 сентября 1870 г. и 14 октября - в честь Лейпцигской битвы 1813 г. С 1915 г. в ноябре ежегодно проводились дни памяти павших (большей частью молодых) в битве при Лангемарке во Фландрии. Вследствие всех этих перемен в системе школьного образования резко ухудшилось качество обучения, получаемого школьниками, что негативно сказалось на их интеллектуальном развитии и жизненных перспективах.

В школьные программы вскоре был внесен дух войны. Школа превратилась в инструмент «воспитания верноподанных, которые в случае необходимости с радостью пожертвуют жизнью ради фатерланда». Так, история преподавалась преимущественно как история войн, которые вели немцы. В изучении географии большое значение приобрели карты территорий, завоеванных немцами, схемы битв, выигранных ими. На уроках математики школьники высчитывали, сколько используется снарядов на фронте в указанное время, сколько кубометров земли будет выкопано при подготовке окопа заданных размеров, сколько можно сэкономить хлеба в рейхе, если все жители тыла три раза в день будут оставлять от своей порции 6 г [9].

Атмосфера «коллективного экстаза», охватившая в начале войны многих немцев, повлияла и на подростков. Учащиеся гимназий, кадеты, члены спортивных объединений подавали коллективные заявления с просьбой отправить их на фронт добровольцами. Многие из них прибавляли себе годы, добиваясь разрешения на вступление в вооруженные силы рейха. Уже в августе 1914 г. в обход правил в запасные батальоны были приняты Штейнгардт из Мангейма (15 лет) и кадет Виллерт из Нойкёльна, которому было 14 лет и 9 месяцев [10]. Газетчики использовали патриотичес- 
кие порывы «детей-солдат» (Kindersoldat), превозносили их самоотверженность и готовность пролить кровь за отечество. Пример подростков давал возможность военным более успешно проводить кампании по вербовке взрослых добровольцев [11].

Особенностью Первой мировой войны является то, что наряду с крупными сражениями на фронтах, гибелью миллионов солдат она впервые в истории втянула в жесточайшее противостояние и общества воюющих государств. Уже в 1915 г. власти ГИ поставили задачу создать «фронт родины» («Hematfront»), который должен был играть роль «фронта тыла», «второго фронта» и внести свой вклад в достижение победы. Его задачей явилась мобилизация всех граждан тыла, включая детей.

Несмотря на тяготы военной жизни, дети порой из последних сил старались помочь взрослым в решении семейных проблем, по возможности заменить отцов, ушедших на фронт. Чтобы поддержать работающих матерей, которым пришлось стать главами семей, они взяли на себя значительную часть домашней работы, опекали младших братьев, сестер и старших родственников. Наряду со взрослыми подростки вели тяжелую борьбу за «каждодневный хлеб» - добывали продукты. Вместе с матерями они многие часы, иногда с полуночи, стояли в длинных очередях в продовольственные лавки. Случалось, получив известие, что продукты заканчиваются, взрослые брали штурмом двери и прилавки магазинов, и в толчее они сбивали детей с ног, опрокидывали их на пол, наносили им физические и моральные травмы.

Дети были широко вовлечены в массовые поездки голодающих горожан в сельскую местность с целью покупки у фермеров (по ценам ниже, чем на черном рынке) продуктов для пополнения крайне скудного рациона семей. В лексиконе немцев в годы войны стало популярным понятие «hamstern», которое буквально переводилось как «торговаться», «мешочничать». Но в годы войны оно стало употребляться в смысле «выторговать», «урвать», «добыть из-под полы», «обжулить», допуская при этом мошенничество и мелкое воровство. Хотя эти поездки были сопряжены с трудностями, взрослые, чаще всего женщины, брали с собой в качестве помощников детей. Сайт «История Вестфалии» содержит описание такой поездки: в каждый уик-энд рано утром изможденные голодом дети с корзинами, сумками, рюкзаками вместе со взрослыми втискивались в доверху набитые людьми вагоны, ехали в тамбурах, порой - с угрозой для жизни - висели на ступеньках вагонов, судорожно вцепившись в поручни, чтобы доехать до сельской местности; задыхаясь, они стремились обогнать поток мешочников, чтобы первыми добраться до крестьянского двора; до позднего вечера, еле волоча ноги, они группками или парами брели от усадьбы к усадьбе, надеясь уговорить фермера продать картофель, сало, шпик, масло, яйца. Вместе со взрослыми дети ночевали в холодных сараях или в шалашах на опушке леса, пристанищах в кустарниках, сооруженных в темноте при свете фонариков. Холодные ночевки, долгие переходы, отсутствие теплой пищи изнуряли детский организм.

Однако присутствие подростков приносило пользу: они охраняли добытые продукты, когда взрослые отлучались, несли доверху нагруженные рюкзачки. Их отправляли вперед на разведку, чтобы выяснить, нет ли поблизости жандармов, которым было предписано «не допускать в интересах отечества несанкционированный вывоз продовольствия» и конфисковать его у мешочников в случае обнаружения [12]. Нередко дети с молчаливого согласия взрослых выступали в роли добытчиков. Пока старшие торговались во дворе с хозяином, подростки в отдаленной части усадьбы старались тайком накопать картофеля, поймать курицу и др. Немецкий писатель Э. Глазер вспоминает в своем автобиографическом романе «Год рождения 1902», изданном в 1928 г., как он 12-летним мальчиком участвовал в поездке за продуктами: «...нам, детям, была по душе эта перемена, потому что она порождала чувство авантюризма. Это было опасно и в то же время прекрасно: выскользнуть с запретно украденными яйцами с фермерского двора, броситься в траву, если где-то вдали всплывала фигура жандарма, и по ударам сердца считать минуты. Это было волшебно и возвышенно - оставить с носом этого жандарма, и после счастливо закончившегося победного рывка быть встреченным матерью в качестве героя» [6. S. 211]. Такие маленькие победы объясняют мотивы охотного участия многих подростков в мешочничестве, несмотря на его тяготы. Поездки давали им возможность хотя бы на время отрешиться от полной лишений жизни в городе, побыть на природе, приобрести новый, порой весьма рисковый жизненный опыт.

В отсутствие отцов, при крайней загруженности большинства матерей, неспособности школы контролировать учащихся, многие из них оказались безнадзорными и заброшенными. Это позволяло подросткам, в первую очередь мальчикам, расширять диапазон свободы и избавляться от надзора и опеки семьи. Война способствовала их раннему прощанию с детством. Эта преждевременно обретенная свобода обусловила рост асоциальных поступков среди подростков и даже криминальных актов, в первую очередь краж продовольствия и топлива. Число осужденных среди них выросло в 1918 г. по сравнению с 1913 г. почти в два раза: с 54,15 тыс. до 99, 5 тыс. [6. S. 210].

В годы войны старшие дети вовлекались в решение важных задач «фронта родины». Так, в условиях острого дефицита рабочей силы в рейхе они использовались как один из ее резервов. В 1918 г. в промышленности Германской империи работали 421 тыс. юношей моложе 16 лет. Почти все они не имели профессионального образования и не обладали квалификацией, но их труд неплохо оплачивался в условиях нехватки кадров [13]. Большинство из них помогали своим заработком семьям, другие использовали свой новый статус, чтобы ослабить семейные связи и обрести бо́льшую самостоятельность. 
Военное руководство рейха формировало в рамках «фронта родины» «школьный фронт», который должен был мобилизовать учащихся для участия в кампаниях по укреплению тыла ради победы рейха в «большой войне». Поскольку у фермеров катастрофически не хватало рабочих рук, осенние каникулы во многих школах переносились на август следующего года, чтобы «более сильные физически учащиеся из старших классов смогли помочь в уборке и захоронении урожая» сельским хозяевам [14. S. 115]. Наибольшей эксплуатации дети подвергались в семьях фермеров, которые вовлекали в производство собственных детей ради наращивания производства. Девочек привлекали к устройству огородов в парках и скверах городов, выращиванию в них овощей, столь необходимых жителям.

В течение всей войны немецкие дети участвовали в кампании по сбору вторичного сырья, так как Германия, оказавшаяся в тисках морской блокады, испытывала его острую нехватку. Школьники регулярно получали задания по сбору металлолома, макулатуры, резины, одежды, тряпья, костей, стекла, любых горючих материалов и старались выполнить их.

Германский рейх, лишенный доступа на внешние финансовые рынки, был вынужден вести войну преимущественно за счет внутренних займов. Первый заем в 4,5 млрд марок был сделан уже в 1914 г. Всего за годы войны правительство сумело получить у собственного населения 9 займов, общая сумма которых составила почти 98 млрд марок [15]. Такого успеха организаторы добились благодаря крупномасштабным вербовочным кампаниям, в которых участвовали и дети. Одетые в специально сшитую военную форму они отрядами ходили по улицам городов и населенных пунктов с броскими плакатами, на которых было написано: «Кто подпишется на военный заем, тот приблизит конец войны». Маленьких немцев отправляли на центральные улицы городов с кружками в руках собирать пожертвования у прохожих. В школе детям давали задания убедить матерей и родственниц сдать свои золотые украшения в приемные пункты в фонд финансирования войны.

В течение всей войны к Рождеству во внеклассное время школьники готовили для фронтовиков так называемые подарки любви (Liebesgabe). В них они вкладывали рисунки, предметы гигиены, кулечки со сладостями, сигареты, самодельные елочные игрушки и пр. Обязательным атрибутом этих подарков были теплые носки, шарфы и перчатки для солдат, связанные девочками [16].

Еще одним невиданным ранее направлением работы с детьми явилась массированная пропаганда, которая была нацелена на воспитание милитаристского, ксенофобского сознания, содействующего их мобилизации [17]. Внедрение в етское сознание подобных идей происходило через наполнение ими содержания образовательных программ, проведение специальных «военных уроков», занятий по военной подготовке учащихся старших классов, вовлечение в кампании национального масштаба. Воспитание в духе милитаризма самых маленьких детей осуществлялось посредством широкого распространения игрушек, являвшихся миниатюрными изображениями военной техники, солдат, лазаретов, окопных сооружений, которые заполонили детские комнаты и уголки. Этой же цели служили детские книги и журналы. Общая численность таких изданий, выпущенных в годы войны, превысила 200 тыс. [17. С. 75].

Война оказала крайне негативное воздействие на детей Германии. Они не знали нормального детства, на годы были лишены нормальной пищи, тепла, полноценного общения с родителями, семейных и школьных поездок, утратили многие возможности для плодотворного физического и духовного развития. Голод и лишения подорвали здоровье большей части детей Германской империи, что сказалось на их будущем. Они внесли немалый вклад в решение задач, поставленных перед «фронтом родины» военным руководством и правительством рейха. Многим подросткам пришлось рано пойти на работу, опекать нуждающихся в помощи членов семьи. Война принесла множеству детей сиротство, но и те, чьи отцы выжили, надолго оставались одинокими в период взросления, не получали родительских советов и наставлений. Даже когда мужчины вернулись домой после войны, их дети нередко чувствовали себя полусиротами, так как сотни тысяч солдат были инвалидами и раненными. Поражение в «большой войне» подорвало психику значительной части солдат рейхсвера, истощило нравственно, поэтому они нередко не могли вернуться к роли главы семьи и ответственно воспитывать детей. Фронтовики принесли в семьи авторитарный стиль общения, который и ранее был присущ немецким семьям. В итоге после возвращения отцов положение многих детей не улучшилось.

\section{ЛИТЕРАТУРА}

1. Wehler H.-U. Das deutsche Kaiserreich 1871-1918. 7. Auflage. Göttingen : Vandenhoeck \& Ruprecht, 1994.

2. Der Erste Weltkrieg Alltag und Propaganda // Politik \& Unterricht. Zeitschrift für die Praxis der politischen Bildung. Hetft 3/4-2013.

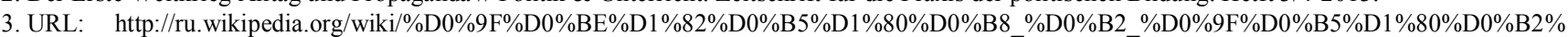
D0\%BE\%D0\%B9_\%D0\%BC\%D0\%B8\%D1\%80\%D0\%BE\%D0\%B2\%D0\%BE\%D0\%B9_\%D0\%B2\%D0\%BE\%D0\%B9\%D0\%BD\%D0\%B (дата обращения: 10.04.2019).

4. Meiners A. Die Stunde der Frauen zwischen Monarchie, Weltkrieg uns Wahlrecht. 1913-1919. München : Sandmann Verlag, 2013.

5. Damals. Das Magazin für Geschichte. 2014. № 3.

6. Flemming Th., Ulrich B. Heimatfront. Zwischen Kriegsbegeisterung und Hungersnot - wie die Deutschen den Ersten Weltkrieg erlebten. München : Bucher Verlag, 2014

7. URL: http://www.deuframat.de/konflikte/krieg-und-aussoehnung/der-erste-weltkrieg-im-kollektiven-gedaechtnis-der-deutschen-und-der-franzosen/ jugend-und-schule-im-krieg/jugendkompanien.html (дата обращения: 10.04.2019). 
8. URL: https://www.erster-weltkrieg.clio-online.de/_Rainbow/documents /einzelne/Luftkrieg14_181.pdf. (дата обращения: 10.04.2019).

9. URL: http://www.hausarbeiten.de/faecher/vorschaü/36006.html (дата обращения: 10.04. 2019).

10. URL: http://www.volksbund.de/fileadmin/img/LV/bayern/PDF/63639_Handreichung_Kindersoldaten.pdf (дата обращения: 10.04.2019).

11. URL: http://www.zeitlupe.co.at/werbung/propaganda.html.1 (дата обращения: 10.04.2019).

12. URL: http://www.lwl.org/westfaelische-geschichte/portal/Internet/finde/langDatensatz.php?urlID=257\&url_tabelle=tab_medien (дата обращения: 10.04.2019).

13. URL: http://www.damals.de/de/8/Erster-Weltkrieg-Kriegspropaganda-in-Kinderbuechern.html?aid=191305\&cp=24\&action=showDetails (дата обращения: 10.04.2019).

14. Kellerhof S.-F. Heimatfront: der Untergang der heilen Welt - Deutschland im Ersten Weltkrieg. Köln : Quadriga, 2014.

15. URL: http://boerse.ard.de/boersenwissen/boersengeschichte-n/die-finanzquelle-des-krieges100.html (дата посещения: 10.04.2019).

16. URL: http://www.fr-online.de/campus/erster-weltkrieg-kinder-propaganda-fuer-kinder,4491992,26915782.html (дата обращения: 10.04.2019).

17. Супрыгина Г.Г. Дети Германии в прицеле пропаганды в годы Первой мировой войны // Тоталитаризм и тоталитарное сознание / под ред. В.С. Шутова. Томск : Кит, 2015.

Galina G. Suprygina. Tomsk State University (Tomsk, Russia). E-mail: askis@ngs.ru

\section{THE CHILDREN OF GERMANY IN THE FIRST WORLD WAR}

Keywords: "front of the homeland" in Germany in the First World War; children.

The problem is, the article is particularly relevant, as in domestic science participation of Germany in the First World War was seen almost exclusively from the military and political point of view. The society of Reich had been explored fragmentary, but the German kids life remains a white stain. The article focuses on the examination of the situation and the role of the children at the "front of the homeland" during the First World War.

The research is based on analyzing in German such scholars as: Flemming Th., Kellerhof S.-F., Meiner A., Ulrich B., Wehler H.-U. These authors had prepared their works to 100-anniversary of the First World War. Internet resources were also used, that were the materials produced by a number of academic and political and educational centers.

The article shows that in connection with the transfer of all resources to the military industry the society situation deteriorated rapidly and children grew up in conditions of hunger, lack of fuel, lack of basic necessities. Doctors documented deterioration of children's health and increased mortality. The quality of teaching became lower due to the shortage of teachers, premises, reducing the training sessions. The most acute problem of rear during the war was hunger, from which about 700 thousand died. German children in the absence of fathers tried to help mothers in search of food, took care of younger siblings, older relatives. Many unaccompanied teenagers often committed antisocial and criminal acts that resulted in an increase in the number of convicted prisoners among them.

During the war children were involved in the achievement of major objectives of the development of the society. With the shortage of workforce in Germany children were used in the war economy, were attracted in the campaign for the collection of recyclable materials, because there was deficit due to the British naval blockade. The Government funded the war through domestic borrowings, which involved children.

The war had a negative impact on children of Germany. They were not aware of normal childhood, their health has been undermined, that was the threat to their future. Many war children became orphans. But after the return of the fathers the situation of many children had not changed radically for the better, as many war veterans returned home disabled, mentally depleted and could not again become heads of families.

\section{REFERENCES}

1. Wehler, H.-U. (1994) Das deutsche Kaiserreich 1871 - 1918. 7th ed. Göttingen: Vandenhoeck \& Ruprecht.

2. Weber, R. (ed.) (2013) Der Erste Weltkrieg Alltag und Propaganda. Vol. $3 / 4$.

3. Wikipedia. (n.d.) [Online] Available from: http://ru.wikipedia.org/wiki/\%D0\%9F\%D0\%BE\%D1\%82\%D0\%B5\%D1\%80\%D0\%B8 $\%{ }_{0} \% \mathrm{D} 0 \% \mathrm{~B} 2 \_\% \mathrm{D} 0 \%$ 9F\%D0\%B5\%D1\%80\%D0\%B2\%D0\%BE\%D0\%B9_\%D0\%BC\%D0\%B8\%D1\%80\%D0\%BE\%D0\%B2\%D0\%BE\%D0\%B9_\%D0\%B2\%D0\%BE $\% \mathrm{D} 0 \% \mathrm{~B} 9 \% \mathrm{D} 0 \% \mathrm{BD} \% \mathrm{D} 0 \% \mathrm{~B}$. (Accessed: 10th April 2019).

4. Meiners, A. (2013) Die Stunde der Frauen zwischen Monarchie, Weltkrieg uns Wahlrecht. 1913-1919. Munich: Sandmann Verlag.

5. Damals. Das Magazin für Geschichte. (2014) 3.

6. Flemming, Th. \& Ulrich, B. (2014) Heimatfront. Zwischen Kriegsbegeisterung und Hungersnot-wie die Deutschen den Ersten Weltkrieg erlebten. Munich: Bucher Verlag.

7. Schneider, G. (n.d.) Der Erste Weltkrieg im kollektiven Gedächtnis der Deutschen und der Franzosen. [Online] Available from: http://www.deuframat.de/konflikte/krieg-und-aussoehnung/der-erste-weltkrieg-im-kollektiven-gedaechtnis-der-deutschen-und-der-franzosen/jugendund-schule-im-krieg/jugendkompanien.html. (Accessed: 10th April 2019).

8. Clio. (n.d.) [Online] Available from: https://www.erster-weltkrieg.clio-online.de/_Rainbow/documents /einzelne/Luftkrieg14_181.pdf. (Accessed: 10th April 2019).

9. Schlott, R. (2005) Kinder und Propaganda im Ersten Weltkrieg. [Online] Available from: http://www.hausarbeiten.de/faecher/vorschau/36006.html. (Accessed: 10th April 2019).

10. Bulitta, E. \& Bulitta, H. (n.d.) Um die Jugend betrogen - Kindersoldaten. [Online] Available from: http://www.volksbund.de/fileadmin/ $\mathrm{img} / \mathrm{LV} /$ bayern/PDF/63639 Handreichung Kindersoldaten.pdf. (Accessed: 10th April 2019).

11. Anon. (n.d.) Kinder und Propaganda. [Online] Available from: http://www.zeitlupe.co.at/werbung/propaganda.html.1. (Accessed: 10th April 2019).

12. LWL. (n.d.) Das Internet-Portal zur Westfälischen Geschichte. [Online] Available from: http://www.lwl.org/westfaelischegeschichte/portal/Internet/finde/langDatensatz.php?urlID=257\&url_tabelle=tab_medien. (Accessed: 10th April 2019).

13. Wissenshaft.de. (2014) Erster Weltkrieg: Kriegspropaganda in Kinderbüchern. [Online] Available from: http://www.damals.de/de/8/ErsterWeltkrieg-Kriegspropaganda-in-Kinderbuechern.html?aid=191305\&cp=24\&action=showDetails. (Accessed: 10th April 2019).

14. Kellerhof, S.-F. (2014) Heimatfront: der Untergang der heilen Welt-Deutschland im Ersten Weltkrieg. Cologne: Quadriga.

15. Boerse.ARD.de. (2014) Die Finanzquelle des Krieges. [Online] Available from: http://boerse.ard.de/boersenwissen/boersengeschichte-n/diefinanzquelle-des-krieges100.html. (Accessed: 10th April 2019).

16. Fr.de. (n.d.) ERster Welkrieg Kinder Propaganda. [Online] Available from: http://www.fr-online.de/campus/erster-weltkrieg-kinder-propagandafuer-kinder,4491992,26915782.html. (Accessed: 10th April 2019).

17. Suprygina, G.G. (2015) Deti Germanii v pritsele propagandy v gody Pervoy mirovoy voyny [Children of Germany in the propaganda focus during WWI]. In: Shutov, V.S. (ed.) Totalitarizm i totalitarnoe soznanie [Totalitarianism and totalitarian consciousness]. Tomsk: Kit. 